\title{
Benefícios do aleitamento materno exclusivo até sexto mês de vida
}

\author{
Benefits of exclusive breastfeeding up to sixth month of life \\ Beneficios de la lactancia materna exclusiva hasta el sexto mes de vida
}

Recebido: 13/05/2021 | Revisado: 18/05/2021 | Aceito: 21/05/2021 | Publicado: 07/06/2021

Tailanne Araújo Caldas

ORCID: https://orcid.org/0000-0001-9782-0205

Centro Universitário Estácio Sergipe, Brasil

E-mail: tailanetati_@hotmail.com.br

Marcel Vinícius Cunha Azevedo

ORCID: https://orcid.org/0000-0002-5312-3333

Centro Universitário Estácio Sergipe, Brasil

E-mail: marcelvinicius49@gmail.com

Ruth Cristini Torres

ORCID: https://orcid.org/0000-0002-8664-192X Instituto de Hematologia e Hemoterapia de Sergipe, Brasil

E-mail: ruthcristini@gmail.com

Weber de Santana Teles

ORCID: https://orcid.org/0000-0003-1770-8278

Instituto de Hemoterapia de Sergipe, Brasil

E-mail: arteecura@hormail.com

Max Cruz da Silva

ORCID: https://orcid.org/0000-0002-6944-5986

Faculdade Pio Décimo, Brasil

E-mail: maxlfi@hotmail.com

Ângela Maria Melo Sá Barros

ORCID: https://orcid.org/0000-0003-4087-3247

Universidade Federal do Rio de Janeiro, Brasil

E-mail: angelsamelo@hotmail.com

Maria Hozana Santos Silva

ORCID: https://orcid.org/0000-0001-5742-5366

Faculdade Ages de Medicina, Brasil E-mail: hosana_p@hotmail.com

André Luiz de Jesus Morais

ORCID: https://orcid.org/0000-0003-4889-8297

Centro Universitário Estácio de Sergipe, Brasil

E-mail: enfermeiro.andre@hotmail.com

Paulo Celso Curvelo Santos Junior

ORCID: https://orcid.org/0000-0001-5834-6782

Universidade Tiradentes, Brasil

E-mail: Paulo.curvelo.jr@gmail.com

Isabelle Borges Primo de Carvalho

ORCID: https://orcid.org/0000-0002-6789-8498

Universidade Tiradentes, Brasil

E-mail: isabelle@laboclinica.med.br

\begin{abstract}
Resumo
Objetivo: Esse estudo teve como objetivo analisar na literatura existente os benefícios do aleitamento materno exclusivo até o sexto mês de vida. Métodos: trata-se de uma revisão integrativa da literatura, baseada em artigos por meio da Biblioteca Virtual em Saúde (BVS), através das bases de dados eletrônicas: Scientific Eletronic Library Online (SciELO) e Literatura Latino-Americana e do Caribe em Ciências da Saúde (LILACS), com o ano de publicação entre 2013 e 2018. Resultados: a busca nas bases de dados consultadas resultou em 82 artigos, porém definiu-se 18 para análise. Assim, após análise dos estudos, foram definidas três categorias para a discussão dos resultados: Benefícios do Aleitamento Materno Exclusivo até o sexto mês de vida, Fatores que levam ao desmame precoce do Aleitamento Materno e Ações desenvolvidas pelos enfermeiros na promoção do aleitamento materno. Conclusão: Evidenciou-se que o aleitamento materno é um alimento completo e insubstituível, refletindo diretamente na qualidade de vida da mãe e do lactante. E, que a enfermagem é fundamental no incentivo a essa prática.
\end{abstract}

Palavras chave: Aleitamento materno; Desmame; Papel do profissional de enfermagem; Leite humano.

\section{Abstract}

Objective: This study aimed to analyze in the existing literature the benefits of exclusive breastfeeding until the sixth month of life. Methods: integrative review of the literature, based on articles through the Virtual Health Library 
(VHL), through the electronic databases: Scientific Electronic Library Online (SciELO) and Latin American and Caribbean Literature in Sciences (LILACS), with the year of publication between 2013 and 2018. Results: the search in the databases consulted resulted in 82 articles, but 18 were defined for analysis. Thus, after analyzing the studies, three categories were defined for the discussion of the results: Benefits of Exclusive Breastfeeding until the sixth month of life, Factors that lead to the early weaning of Breastfeeding and Actions developed by nurses in the promotion of breastfeeding. Conclusion: It was evidenced that breastfeeding is a complete and irreplaceable food, directly reflecting the quality of life of the mother and the infant. And, that nursing is fundamental in encouraging this practice.

Keywords: Breastfeeding; Weaning; Role of the nursing professional; Human milk.

\section{Resumen}

Objetivo: Este estudio tuvo como objetivo analizar en la literatura existente los beneficios de la lactancia materna exclusiva hasta el sexto mes de vida. Métodos: es una revisión integradora de la literatura, a partir de artículos mediante de la Biblioteca Virtual en Salud (BVS), a través de las bases de datos electrónicas: Biblioteca Científica Electrónica en Línea (SciELO) y Literatura Latinoamericana y Caribeña en Ciencias de la Salud (LILACS), con el año de publicación entre 2013 y 2018. Resultados: la búsqueda en las bases de datos consultadas arrojó 82 artículos, pero se definieron 18 para su análisis. Así, luego del análisis de los estudios, se definieron tres categorías para la discusión de los resultados: Beneficios de la Lactancia Materna Exclusiva hasta el sexto mes de vida, Factores que conducen al destete temprano de la Lactancia Materna y Acciones desarrolladas por enfermeras en la promoción de la lactancia materna. Conclusión: Se hizo evidente que la lactancia materna es un alimento completo e insustituible, reflejando directamente la calidad de vida de la madre y el lactante. Y que la enfermería es fundamental para fomentar esta práctica.

Palabras clave: Amamantamiento; Destete; Rol del profesional de enfermería; Leche humana.

\section{Introdução}

O aleitamento materno é nutriente com benefícios essenciais para o bebê até o sexto mês de vida. Entretanto, estimula ainda mais o vínculo entre a mãe e o bebê, e reduzindo riscos de doenças, visto que o leite materno promove fatores que estão relacionados à estrutura psicológica, física e social (Machado et al., 2016).

Desde as primeiras horas de vida o leite materno é a forma mais segura, completa e eficaz para a ampliação adequado da criança até o sexto mês de vida, suprindo todas as necessidades dessa faixa etária (Barreto, Silva \& Chirstofel, 2015).

Dessa forma os benefícios do aleitamento materno no binômio mãe-filho, que contribuem para o desenvolvimento do lactante destacam-se pela digestibilidade, ausência de produtos que possam causar alergia, prevenção de infecções e diarreia. Além de fatores econômicos que possam levar a família a ter uma diminuição nos custos financeiros. Estudos apontam a importância da amamentação na saúde da mulher diminuindo os riscos de câncer de mama ou ovário, doenças cardiovasculares, perda de peso voltado à forma física, diminuição do sangramento e anemia (Coca et al., 2018).

De acordo com Rocha et al. (2016) desde o início do pré-natal até a puericultura a genitora recebe orientações voltadas sobre o aleitamento materno e seus benefícios. A falta de experiência e mitos que envolvem o processo de lactação acaba na maioria das vezes indeferindo na assistência prestada. Portanto, é de suma importância que o enfermeiro esteja apto a esclarecer dúvidas a respeito da amamentação, estabelecendo uma escuta ativa e compreender os medos.

Carneiro et al. (2014) afirma que o desmame precoce é uns dos fatores de risco associados à prática, na suspensão do aleitamento materno exclusivo até sexto mês de vida, na iniciação de outros alimentos. Umas das causas materna que contribuir é o fator anatômico do mamilo, exemplo: Mamilos planos e invertidos acabam também dificultando a pega correta.

Assim, os profissionais de saúde da atenção primária têm como tática o incentivo do leite materno, sendo essa estratégia simples e cientificamente comprovada, traz vantagens para o crescimento infantil, diminuindo as taxas de desmame precoce. Quando os profissionais de saúde estão confiantes em suas próprias habilidades para apoiar as mulheres que amamentam, estão mais propensos a promover positivamente o aleitamento materno e oferecer apoio às mães (Almeida, Luz \& Ued, 2014).

O leite materno exclusivo é um método natural de planejamento familiar, estimula a presença da prolactina, esse hormônio inibi a ovulação, diminuindo a chance de fertilidade. O correto seria iniciar o método contraceptivo hormonal após o 
sexto mês de vida e nesse período o aleitamento materno exclusivo. Isto sugere que o bebê mame exclusivamente na mãe, de manhã à noite (Mesquita et al., 2016). Embora, alguns danos venham sido considerados, o predomínio de práticas do desmame precoce no Brasil ainda ocorre, sendo considerado apenas $41 \%$ de lactentes com idade inferior a 6 meses estão em aleitamento materno exclusivo, a prática da interrupção do aleitamento materno precocemente pode estar relacionada aos meios socioculturais em que a família da criança está adequada. (Nascimento et al., (2020).

A amamentação requer o apoio do profissional, com o acompanhamento familiar direcionado ao estado emocional da genitora e o lactante, proporcionando um ambiente adequado e assim um suporte essencial para o equilíbrio emocional e sossegado para esse momento (Schimoda et al., 2013).

A justificativa para escolha do tema para a pesquisa, é por almejar contribuir para uma reflexão futura para assistência qualificada, visto que o profissional de enfermagem dotado de conhecimento científico e habilidades práticas desempenha um papel fundamental para promoção da saúde presente/futuro.

O estudo tem como objetivo analisar na literatura existente os benefícios do aleitamento materno exclusivo até o sexto mês de vida, evidenciar fatores que levam ao desmame precoce do aleitamento materno e especificar ações desenvolvidas pelos enfermeiros na promoção do aleitamento materno.

\section{Metodologia}

A pesquisa caracteriza-se como revisão integrativa de literatura, a qual reúne e resume o conhecimento científico já produzido sobre o tema investigado, ou seja, permite buscar, avaliar e sintetizar as evidências disponíveis para contribuir com o desenvolvimento do conhecimento na temática.

Para elaboração da presente revisão integrativa foram percorridas as seguintes etapas: escolha do objetivo da pesquisa; estabelecimento dos critérios de inclusão e exclusão das publicações; busca na literatura; análise e categorização dos estudos; apresentação e discussão dos resultados (Mendes, Silveira \& Galvão, 2008).

Nesta perspectiva, o estudo teve como questões norteadoras: Quais os benefícios do aleitamento materno até o sexto mês de vida? Que fatores podem levar ao desmame precoce do aleitamento materno? Que ações são desenvolvidas pelos enfermeiros na promoção do aleitamento materno?

A busca pelos artigos foi realizada no início do mês de novembro e o termino na metade do mês de fevereiro de 2020 por meio da Biblioteca Virtual em Saúde (BVS), através das bases de dados eletrônicas: Base de Dados em Enfermagem (BDENF), Scientific Eletronic Library Online (SciELO) e Literatura Latino-Americana e do Caribe em Ciências da Saúde (LILACS).

A escolha se justifica por se tratarem de bases atualizadas, confiáveis e relacionadas com a área da enfermagem. Foram utilizados os Descritores em Ciência da Saúde (DeCS): "Desmame precoce", "papel do profissional de enfermagem", "aleitamento materno", atendendo aos seguintes critérios de inclusão: artigos que abordaram os benefícios do aleitamento materno exclusivo até do sexto mês de vida; artigos em bases de dados nacionais; artigos originais e em português; abrangência entre 2013 a 2018, os critérios de exclusão foram: trabalhos de conclusão de curso, teses e dissertações.

Para análise dos dados foi elaborado um quadro sintético destinado à coleta das informações, visando facilitar a identificação e análise dos aspectos considerados mais relevantes ao objetivo da pesquisa. Assim, os dados foram ordenados de forma decrescente em relação ao ano de publicação, contendo as seguintes variantes: ano de publicação; periódico; autor (es); título e objetivos.

Selecionada e analisada toda a bibliografia considerada pertinente ao objetivo proposto para a pesquisa, foi realizada a leitura de cada material e destacados os aspectos mais relevantes, tendo em vista a viabilidade da pesquisa, contemplando os pontos principais do estudo. 
Os resumos foram avaliados, e as produções que atenderam os critérios previamente estabelecidos, foram selecionadas para este estudo, e lidas na íntegra. A busca nas bases de dados consultadas resultou em 82 artigos. A seleção inicial considerando os critérios de inclusão e exclusão definiu-se apenas 18 para análise, especialmente, pelo objetivo do presente estudo.

Por se tratar de uma pesquisa bibliográfica, os dados obtidos seguiram princípios éticos da Lei $\mathrm{N}^{\circ} 12.853$, de 14 de agosto de 2013 que regulamenta os direitos autorais.

\section{Resultados}

Foram encontrados 82 artigos nas bases de dados dos quais, após utilizar os critérios de inclusão e exclusão, foram selecionados 18 artigos para análise. Sendo que artigos 09(50\%) foram encontrados no SciELO, 05(27,77\%) no LILACS e 04(22,22\%) na BDENF. Como mostra o Quadro 1.

Quadro 1 - Distribuição dos artigos conforme o objetivo da pesquisa (2013 a 2018) - Aracaju/SE, 2021.

\begin{tabular}{|c|c|c|c|}
\hline Bases de dados & Encontrados & Excluídos & Amostra final \\
\hline BDENF & 12 & 08 & $04(22,22 \%)$ \\
\hline LILACS & 20 & 15 & $05(27,77 \%)$ \\
\hline SCIELO & 50 & 41 & $09(50 \%)$ \\
\hline Total & 82 & 64 & $18(100 \%)$ \\
\hline
\end{tabular}

Fonte: Caldas, AT, et al., (2021).

Quanto os estados das publicações pesquisadas, predominou na região sudeste com $80 \%$ (ênfase no estado de São Paulo com $61 \%$ das publicações e $19 \%$ no estado de Santa Catarina), na região norte 5\%, já na região Sul com $12 \%$ conforme mostrado no Gráfico 1.

Gráfico 1 - Resultado da pesquisa com as regiões dos artigos pesquisados nas bases de dados eletrônicos disponíveis na internet. Aracaju/SE, 2021.

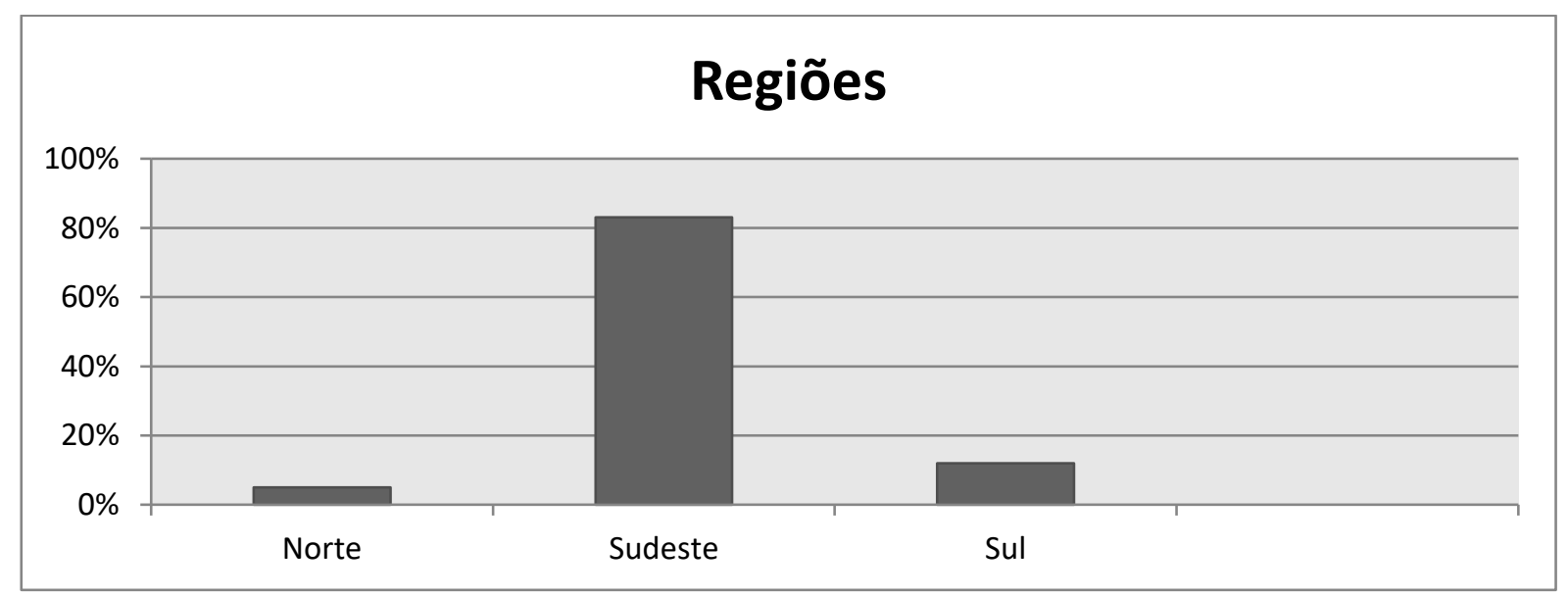

Fonte: Caldas, AT, et al., (2021).

Com relação aos artigos selecionados para a análise dos dados, foi desenvolvido um instrumento de coleta de dados, apresentado abaixo, com os estudos mais relevantes para a construção deste artigo. Os Quadros 2, 3 e 4, destacam os artigos mais utilizados nas categorias discutidas. 
Quadro 2 - Artigos selecionados para análise dados. Aracaju/SE, 2021.

\begin{tabular}{|c|c|c|c|c|}
\hline ANO & PERIÓDICO & AUTORES & TÍTULO & OBJETIVOS \\
\hline 2018 & Coca KP. & COCA et al. & $\begin{array}{l}\text { Conjunto de medidas para o } \\
\text { incentivo do aleitamento materno } \\
\text { exclusivo } \\
\text { evidências de revisões sistemáticas. }\end{array}$ & $\begin{array}{l}\text { Identificar as principais recomendações } \\
\text { encontradas em revisões sistemáticas } \\
\text { relacionadas aos fatores de proteção do } \\
\text { aleitamento materno exclusivo intra- } \\
\text { hospitalar. }\end{array}$ \\
\hline 2017 & $\begin{array}{l}\text { Revista saúde em } \\
\text { foco. }\end{array}$ & SANTOS et al. & $\begin{array}{l}\text { Os benefícios da amamentação para } \\
\text { a saúde da mulher. }\end{array}$ & $\begin{array}{l}\text { E para a mulher o ato de amamentar atua } \\
\text { diminuindo as chances de um possível } \\
\text { desenvolvimento de um câncer de mama } \\
\text { e de ovário, a involução uterina pós-parto } \\
\text { mais rápida e entre outros inúmeros } \\
\text { benefícios que serão abordados neste } \\
\text { artigo cientifico. }\end{array}$ \\
\hline 2016 & $\begin{array}{l}\text { Revista o mundo } \\
\text { saúde. }\end{array}$ & LIMA et al. & $\begin{array}{l}\text { A influência de crenças e tabus } \\
\text { alimentares na amamentação. }\end{array}$ & $\begin{array}{l}\text { Verificar as diferenças nas práticas } \\
\text { alimentares durante a lactação dessa } \\
\text { população e se houve orientação em } \\
\text { relação ao aleitamento materno }\end{array}$ \\
\hline 2016 & $\begin{array}{l}\text { Revista Esc. } \\
\text { Enferm. USP. }\end{array}$ & $\begin{array}{l}\text { MACHADO et } \\
\text { al. }\end{array}$ & $\begin{array}{ll}\text { Aleitamento } & \text { materno: } \\
\text { conhecimento e prática. }\end{array}$ & $\begin{array}{l}\text { Caracterizar as práticas de promoção ao } \\
\text { aleitamento materno. }\end{array}$ \\
\hline 2013 & $\begin{array}{ll}\text { Acta } & \text { Paul } \\
\text { Enferm. } & \end{array}$ & $\begin{array}{l}\text { SCHIMODA et } \\
\text { al. }\end{array}$ & $\begin{array}{l}\text { Necessidades de saúde de nutrizes e } \\
\text { qualidade de vida. }\end{array}$ & $\begin{array}{l}\text { Relacionar as necessidades de saúde e a } \\
\text { qualidade de nutrizes. }\end{array}$ \\
\hline 2013 & $\begin{array}{l}\text { Revista Rede de } \\
\text { Enfermagem do } \\
\text { Nordeste }\end{array}$ & TEXEIRA et al. & $\begin{array}{l}\text { Percepções de primíparas sobre } \\
\text { orientação no pré-natal acerca do } \\
\text { aleitamento materno. }\end{array}$ & $\begin{array}{l}\text { Analisar percepções de primíparas sobre } \\
\text { arientações recebidas no pré-natal acerca } \\
\text { do aleitamento materno. }\end{array}$ \\
\hline
\end{tabular}

Fonte: Caldas, AT, et al., (2021).

Quadro 3-Fatores que levam ao desmame precoce no aleitamento materno. Aracaju/SE, 2021.

\begin{tabular}{|c|c|c|c|c|}
\hline ANO & PERIÓDICO & AUTORES & TÍTULO & OBJETIVOS \\
\hline 2016 & $\begin{array}{l}\text { Revista cientifica da } \\
\text { amercica latina }\end{array}$ & $\begin{array}{l}\text { PRADO; } \\
\text { FABBRO; } \\
\text { FERREIRO }\end{array}$ & $\begin{array}{l}\text { Desmame precoce na } \\
\text { perspectiva de puérperas: Uma } \\
\text { abordagem dialógica. }\end{array}$ & 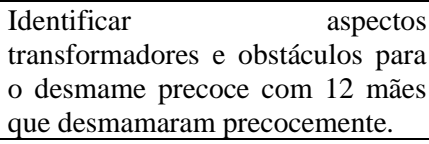 \\
\hline 2015 & $\begin{array}{l}\text { Revista Eletr. de } \\
\text { Enfermagem. }\end{array}$ & $\begin{array}{l}\text { BARRETO; } \\
\text { SILVA; } \\
\text { CHRISTOFFE }\end{array}$ & $\begin{array}{l}\text { Aleitamento materno: Visão } \\
\text { das puérperas. }\end{array}$ & $\begin{array}{l}\text { Geram uma enorme ansiedade e } \\
\text { precipitação na hora em que as } \\
\text { mães decidem se vão permanecer } \\
\text { ou não com o aleitamento materno } \\
\text { exclusivo. }\end{array}$ \\
\hline 2014 & $\begin{array}{l}\text { Revista de saúde } \\
\text { pública }\end{array}$ & MACHADO et al. & $\begin{array}{lr}\text { Determinantes do } & \text { abandono } \\
\text { do aleitamento } & \text { materno } \\
\text { exclusivo: } & \text { fatores } \\
\text { psicossociais. } & \\
\end{array}$ & $\begin{array}{l}\mathrm{O} \text { objetivo deste estudo foi } \\
\text { relacionar necessidades de saúde e } \\
\text { a qualidade de nutrizes. }\end{array}$ \\
\hline 2014 & $\begin{array}{l}\text { Revista ciências da } \\
\text { saúde }\end{array}$ & CARNEIRO et al. & $\begin{array}{l}\text { Pratica do aleitamento } \\
\text { materno por puérperas: } \\
\text { Fatores de risco para o } \\
\text { desmame precoce. }\end{array}$ & $\begin{array}{llr}\text { Compreender a prática do } & \text { na } \\
\text { aleitamento materno } & \text { na } \\
\text { perspectiva de puérperas } & \\
\text { descrever os fatores de risco } \\
\text { associados ao desmame precoce. }\end{array}$ \\
\hline 2014 & Revista saúde pública & BUCCINI et. al. & $\begin{array}{l}\text { Determinantes do uso de } \\
\text { chupeta e mamadeira. }\end{array}$ & $\begin{array}{l}\text { Analisar os fatores associados ao } \\
\text { uso de chupeta e/ou mamadeira em } \\
\text { lactentes menores de um ano. }\end{array}$ \\
\hline 2014 & $\begin{array}{l}\text { Revista } \\
\text { pública. }\end{array}$ & ESTEVES et al. & $\begin{array}{l}\text { Fatores associados a a } \\
\text { amamentação na primeira hora } \\
\text { de vida. }\end{array}$ & $\begin{array}{l}\text { Fatores de risco independentes } \\
\text { para a amamentação na primeira } \\
\text { hora de vida. }\end{array}$ \\
\hline
\end{tabular}

Fonte: Caldas, AT, et al., (2021). 
Quadro 4 - Ações desenvolvidas pelos enfermeiros na promoção do aleitamento. ARACAJU/SE, 2021.

\begin{tabular}{|c|c|c|c|c|}
\hline ANO & $\begin{array}{l}\text { PERIÓDIC } \\
\text { O }\end{array}$ & AUTORES & TÍTULO & OBJETIVOS \\
\hline 2016 & $\begin{array}{l}\text { Rev. Cient } \\
\text { Sena Aires }\end{array}$ & $\begin{array}{l}\text { MESQUITA et } \\
\text { al. }\end{array}$ & $\begin{array}{l}\text { Atribuições de enfermeiros na } \\
\text { orientação de lactentes acerca do } \\
\text { aleitamento materno. }\end{array}$ & $\begin{array}{l}\text { Identificar as atribuições do enfermeiro no } \\
\text { processo de conscientização do aleitamento } \\
\text { materno para com as gestantes. }\end{array}$ \\
\hline 2016 & $\begin{array}{l}\text { Revista de } \\
\text { Enfermagem } \\
\text { conteporânea }\end{array}$ & $\begin{array}{l}\text { MARINHO; } \\
\text { ANDRADE; } \\
\text { ABRÃO }\end{array}$ & $\begin{array}{l}\text { A atuação do(a) enfermeiro(a) na } \\
\text { promoção, incentivo e apoio ao } \\
\text { aleitamento materno. }\end{array}$ & $\begin{array}{l}\text { É analisar a atuação do(a) enfermeiro(a) na } \\
\text { promoção, incentivo e apoio ao aleitamento } \\
\text { materno. }\end{array}$ \\
\hline 2016 & $\begin{array}{l}\text { Revista } \\
\text { contexto \& } \\
\text { Saúde. }\end{array}$ & ROCHA et al. & $\begin{array}{l}\text { O enfermeiro da estratégia de saúde } \\
\text { da família como promotor do } \\
\text { aleitamento materno. }\end{array}$ & $\begin{array}{l}\text { Analisa as ações de promoção } \\
\text { de saúde voltadas para o Aleitamento } \\
\text { Materno Exclusivo (AME) realizado por } \\
\text { enfermeiros da Estratégia Saúde da Família } \\
\text { (ESF), no ano de 2015. }\end{array}$ \\
\hline 2015 & $\begin{array}{ll}\text { Esc } & \text { Anna } \\
\text { Nery } & \end{array}$ & AZEVEDO et al. & $\begin{array}{l}\text { O manejo clínico da amamentação: } \\
\text { saberes dos enfermeiros. }\end{array}$ & $\begin{array}{l}\text { Discutir o saber do enfermeiro no manejo } \\
\text { clínico da amamentação, visando os } \\
\text { benefícios do aleitamento materno na saúde } \\
\text { da mulher e da criança. }\end{array}$ \\
\hline 2015 & $\begin{array}{l}\text { Revista Paul } \\
\text { Pediatr. }\end{array}$ & $\begin{array}{l}\text { ALMEIDA; } \\
\text { LUZ; UED }\end{array}$ & $\begin{array}{l}\text { Apoio ao aleitamento materno pelos } \\
\text { profissionais de saúde: revisão } \\
\text { integrativa da literatura. }\end{array}$ & $\begin{array}{l}\text { Fazer uma revisão da literatura para avaliar } \\
\text { a prática de profissionais de saúde na } \\
\text { promoção e no apoio à amamentação. }\end{array}$ \\
\hline 2013 & $\begin{array}{ll}\text { Revista } & \\
\text { saúde } \\
\text { debate }\end{array} \quad$ em & BATISTA et al. & 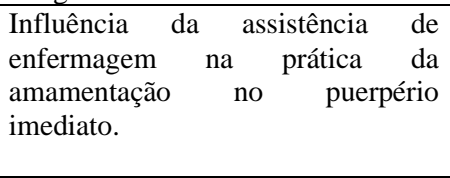 & $\begin{array}{l}\text { Compreender a prática do enfermeiro, como } \\
\text { suporte social, em relação ao aleitamento } \\
\text { materno, esta pesquisa qualitativa } \\
\text { investigou } 16 \text { mulheres que viveram a } \\
\text { amamentação. }\end{array}$ \\
\hline
\end{tabular}

Fonte: Caldas, AT, et al., (2021).

Assim, após análise dos estudos, foram definidas três categorias para a discussão dos resultados: Benefícios do Aleitamento Materno Exclusivo até o sexto mês de vida, Fatores que levam ao desmame precoce do Aleitamento Materno e Ações desenvolvidas pelos enfermeiros na promoção do aleitamento materno.

\section{Discussão}

\section{Benefícios do Aleitamento Materno exclusivo até o sexto mês de vida}

É importante destacar que a amamentação apresenta significado considerado eficaz e benéfico para a saúde da mulher e da criança trazendo inúmeras vantagens para ambos como o fortalecimento do vínculo afetivo mãe-filho, a proteção do sistema imunológico do recém-nascido (Santos et al., 2017).

Pela constituição das unidades estruturais que compõem o leite materno e agem de forma protetora no neonato, o sistema enteromamário da mulher que se encontra na fase de lactação começa a executar funções quando patógenos estão próximos de mucosas do intestino e aparelho respiratório, sendo assim, fagocitados por macrófagos, é a partir deste mecanismo de ação que ocorre a estimulação de linfócitos T, possibilitando a diferenciação de linfócitos B. (Silva et al., 2020)

Foi observado que as mulheres que relataram ter vivenciado algum problema emocional durante a amamentação foram as que pontuaram menor escore de qualidade de vida no domínio psicológico, sendo estatisticamente significativo. A intensidade com que as nutrizes vivem seus sentimentos de alegria ou tristeza, tranquilidade ou ansiedade dá o tom a qualidade de vida e são reflexos de seu contexto familiar e social ampliado (Schimoda et al., 2013).

$\mathrm{Na}$ amamentação, o contato físico é maior e proporciona à mãe e ao bebê momento de proximidade diária. As mulheres possuem a capacidade de gerar filhos e vocação de cuidar, dedicando mais tempo ao filho, e mantendo os primeiros laços emocionais com os estes. A mãe é a principal dispensadora de amor para o recém-nascido (Teixeira et al., 2013).

Em relação aos alimentos considerados benéficos a produção de leite verificou-se que os líquidos, frutas, verduras e legumes, milho e derivados, feijão, arroz e carne são apontados pelas mães das duas unidades avaliadas como benéficos, entretanto, o leite apresentou diferença estatística entre as unidades avaliadas (Lima et al., 2016). 
O leite materno exclusivo é um método natural de planejamento familiar, estimula a presença da prolactina, esse hormônio inibi a ovulação, diminuindo a chance de fertilidade. O correto seria iniciar o método contraceptivo hormonal após o sexto mês de vida e nesse período o aleitamento materno exclusivo. Isto sugere que o bebê mame exclusivamente na mãe, de manhã à noite (Mesquita et al., 2016).

\section{Fatores que levam ao desmame precoce do aleitamento materno}

No estudo realizado por Carneiro et al. (2014), a participação ativa das puérperas, não apenas recebendo e aceitando a orientação, mas se conscientizando e refletindo sobre a importância das mesmas, de modo que se sintam seguras e tenham iniciativa para estabelecer o contato com o filho. Esse é outro campo de intervenção da equipe de saúde como um todo, capacitando-se para, por meio de ações educativas, prepare as mães para o aleitamento durante o pré-natal.

Foram identificados, nas falas das mães, alguns mitos alistados ao leite materno, tais como: leite materno é fraco, não sustenta, provoca cólicas no bebê e que altas temperaturas corporais e agitação materna interferem no leite materno. Esses elementos são obstáculos que acarretam o desmame precoce (Prado, Fabro \& Ferreira, 2016).

Com o aumento dos números da pandemia do novo coronavírus, o aleitamento materno foi associado a um meio de transmissão da COVID-19. Os impactos dessas notícias preocupam diversas mães de lactentes, até o momento (Calil et.al., 2020).

Segundo a OMS, (2020) as mães infectadas são indicadas a seguir com a amamentação, permanecendo juntos e oferecendo o contato entre a sua pele e a da criança para estabelecer o contato enquanto ofertam o leite materno, ainda que, a mãe ou ambos estejam com suspeita ou infectados pelo novo coronavírus, as vantagens da amamentação excedem os riscos de transmissão, portanto, o desmame precoce não deverá ser considerado.

A cesariana é uns dos fatores de risco mais consistentemente associado a não amamentação na primeira hora de vida, interrompendo o ato (Esteves et al., 2014). Já Barreto, Silva e Chirstofel (2015) afirmam que as puérperas sentiram dificuldade para amamentar e descreveram, como problemas, as dificuldades na pega, dor nos mamilos/fissura, posicionamento incorreto do bebê ao seio, falta de preparo do mamilo, e insegurança para amamentar e ingurgitamento mamário.

Os determinantes do uso de bicos artificiais em uma modelo representativa de crianças residentes nas capitais brasileiras, com o benefício de classificar esse uso em três categorias (chupeta e/ou mamadeira), permitindo prosseguir nos conhecimentos sobre o emprego desses objetos que podem intervir negativamente na amamentação e na saúde das crianças (Buccini, Benício \& Venâncio, 2014).

Em sua pesquisa, Machado et al. (2014), afirmam que a maioria dos determinantes ao abandono do aleitamento materno exclusivo são de mulheres diagnosticadas com sintomas de depressão pós-parto, espera com quatro meses após o parto que estivessem em tratamento e os sintomas depressivos diminuídos.

\section{Ações desenvolvidas pelos enfermeiros na promoção do aleitamento materno}

As atuações de promoção, apoio e estímulo ao aleitamento materno quando realizadas no pré-natal e administradas por profissionais habilitados se torna um ambiente ideal para explicação de dúvidas e redução da ansiedade (Marinho, Andrade \& Abrão, 2016).

Cabe ao enfermeiro promover a correção dos problemas como elemento do cuidado eficaz do manejo clínico do aleitamento materno. Na amamentação da ideia de confiança, ou seja, o oferecimento do seu apoio, já que ele necessita estar associado quando a nutriz precisar de sua direção ou de aconselhamento para uma técnica adequada na amamentação (Azevedo et al., 2015). 
Para Rocha et al. (2016), o enfermeiro da atenção básica tem uma atitude mais associada à mulher durante o ciclo gravídico-puerperal e preenche ação enorme nos programas de educação em saúde, de maneira especial ao organizar à grávida para o aleitamento, impedindo dúvidas e possíveis complicações. Mesquita et al. (2016) relata sobre as atribuições do papel da enfermagem frente adesão do aleitamento enfatizando a mulher brasileira no desempenho da amamentação, benefícios para o lactente, e causas que levam ao desmame precoce.

Já Batista, Farias e Melo (2013) o puerpério imediato é determinante para o sucesso da amamentação, pois é quando as mães encaram os maiores problemas com o aleitamento materno, a adaptação da mãe ao recém-nascido e vice-versa, os cuidados em geral, etc. Na pesquisa demonstrou que nesta etapa existiu certo distanciamento do enfermeiro como apoio social capacitado.

Todos os profissionais, sem exceção, deveriam ser contemplados em suas disciplinas de formação, com valor absoluto que confirmassem a importância de se envolverem parâmetros interdisciplinares de auxílio com o aleitamento materno. As instituições de ensino necessitam contribuir para esse processo (Almeida, Luz \& Ued, 2015).

\section{Considerações Finais}

Através da observação realizada no presente estudo evidenciou que o aleitamento materno é uma prática fundamental para o crescimento da criança protegendo sua saúde, suprindo todas as carências nutricionais, afastando problemas como a desnutrição entre outros.

Diante das pesquisas realizadas ainda não foi comprovado a transmissão vertical da COVID-19 por meio do leite materno. Em recém-nascidos o risco de transferência do vírus é reduzido, o processo infeccioso se apresenta tênue ou sem sintomas, entretanto a não amamentação e a separação da mãe e do bebê poder ser relevantes. Diante do fato supracitado a COVID-19 em bebês e crianças, demonstra uma atemorização diminuta de conservação da vida em relação a outras infecções, no qual o leite materno defende.

Foi percebido que algumas gestantes durante o pré-natal e no puerpério propendem a realizar o desame precocemente devido a informações equivocadas sobre a transmissibilidade das doenças infecciosas através do aleitamento materno.

$\mathrm{O}$ enfermeiro tem papel de suma importância no atendimento das necessidades da nutriz, auxiliando com os conhecimentos adquiridos no decorrer dos anos acerca de vivências pessoais, e saberes populares, promovendo condutas satisfatórias em relação a saúde, incentivo ao aleitamento materno peculiar até o sexto mês de vida.

Conclui-se que esta pesquisa sirva de modelo para uma reflexão a profissionais e coordenadores que atuam diretamente no atendimento da gestante, propiciando qualidade nos atendimentos e serviços prestados à puérpera e recémnascido, provendo ações que venham a fortalecer à prática da amamentação.

\section{Referências}

Almeida, J. M., Luz, S. D. A. B., \& Ued, F. D. V. (2015). Apoio ao aleitamento materno pelos profissionais de saúde: revisão integrativa da literatura. Revista Paulista de Pediatria, v. 33(3), 355-62.

Azevedo, A. R. R., et al. (2015). O manejo clínico da amamentação: saberes dos enfermeiros. Escola Anna Nery, Rio de Janeiro. 19(3), 439-45.

Batista, K. R. D. A., et al. (2013). Influência da assistência de enfermagem na prática da amamentação no puerpério imediato. Saúde debate, Rio de Janeiro, 37(96), 130-138

Buccini, G. D. S., et al. (2014). Determinantes do uso de chupeta e mamadeira. Revista Saúde Pública, São Paulo, 48(4), 571-571.

Carneiro, L. M. D. M., et al. (2014). Prática do aleitamento materno por puérperas: atores de risco para o desmame precoce. Ciências da Saúde, Santa Catarina, 15(2), 239-248.

Coca, K. P., et al. (2018). Conjunto de medidas para o incentivo do aleitamento materno exclusivo intra-hospitalar: evidências de revisões sistemáticas. Revista Paulista de Pediatria, São Paulo, 36(2), 214-220. 
Research, Society and Development, v. 10, n. 6, e47310616074, 2021

(CC BY 4.0) | ISSN 2525-3409 | DOI: http://dx.doi.org/10.33448/rsd-v10i6.16074

Esteves, T. M. B., et al. (2014). Fatores associados à amamentação na primeira hora de vida: revisão sistemática. Revista Saúde Pública, Rio de Janeiro, 48(4), 697-703.

Lima, M. M. L., et al. (2016). A influência de crenças e tabus alimentares na amamentação. O Mundo da Saúde, São Paulo, $40(2), 221-229$.

Machado, M. C. M., et al. (2014). Determinantes do abandono do aleitamento materno exclusivo: fatores psicossociais. Revista Saúde Pública, São Paulo, 48(6), 985-994.

Marinho, M. D. S., Andrade, E. N. D., \& Abrão, A. C. F. B. V. (2016). A atuação do(a) enfermeiro(a) na promoção, incentivo e apoio ao aleitamento materno. Revista de Enfermagem Contemporânea, São Paulo, 4(2), 189-198.

Mendes, K. D. D., Silveira, R. C. C. P., \& Galvão, C. M. (2008). Revisão integrativa: método de pesquisa para a incorporação de evidências na saúde e na enfermagem. Texto \& contexto Enfermagem, Florianópolis, 17(4), 758-764.

Mesquita, A. L., et al. (2016). Atribuições de enfermeiros na orientação de lactentes acerca do aleitamento materno. Revista Cientifica Sena Aires, São Paulo, $5(2), 158-70$.

Prado, C. V. C., Fabro., M. R. C., \& Ferreiro, G. I. F. (2016). Desmame precoce na perspectiva de puérperas: Uma abordagem dialógica. Texto Contexto Enfermagem, São Paulo, 25(2), 2-9.

Rocha, F. A. A., et al. (2016). O enfermeiro da estratégia de saúde da família como promotor do aleitamento materno. Revista Contexto \& Saúde, Porto Alegre, 16(31), 16-24.

Santos, G. C. D. P., et al. (2017). Os benefícios da amamentação para a saúde da mulher. Revista Saúde em Foco, São Paulo, 4(9), 225-229.

Schimoda, G. T., et al. (2013). Necessidades de saúde de nutrizes e qualidade de vida. Academia Paulista de Enfermagem, São Paulo, 26(3), $213-218$.

Teixeira, M. M., et al. (2013). Percepções de primíparas sobre orientações no pré-natal acerca do aleitamento materno. Revista Rede de Enfermagem do Nordeste. Fortaleza. 14(1), 179-186.

Moraes, B. A., et al. (2021). Amamentação nos seis primeiros meses de vida de bebês atendidos por Consultoria em Lactação. Rev. Latino-Am. Enfermagem, Ribeirão Preto, 29, e3412.

Carreiro, J. A., et al. (2018). Dificuldades relacionadas ao aleitamento materno: análise de um serviço especializado em amamentação. Acta paul. enferm., São Paulo, 31(4), 430-438.

Silva, D. I. S., et al. (2020). The importance of breastfeeding in the immunity of the newborn. Research, Society and Development, 9(7): 1-14, e664974629.

Nascimento, G. M., et al. (2020) Apoio social e práticas de aleitamento materno: um estudo transversal. Research, Society and Development, 9(7), e863974943.

Calil, V. M., et al. (2020). Orientação sobre amamentação durante a pandemia de Covid-19. Revista de Associação Médica Brasileira, 66 (4), $541-546$.

Martins-Filho P. R., et al. (2020) To breastfeed or not to breastfeed? Lack of evidence on the presence of SARSCoV-2 in breastmilk of pregnant women with COVID-19. Rev Panam Salud Publica. 44:e59.

Organização Pan-Americana da Saúde, Aleitamento materno e a doença causada pelo novo coronavírus (COVID-19). Informações científicas, 2020. OPASW/BRA/COVID-19/20-091 